\title{
FRANÇOIS SIMIAND. Da teoria à realidade econômica (1).
}

Um historiador não é um economista. Isso não é ncvidade. E se chamo atenção para um notável curso de Economia Política que acaba de ser publicado, ou mais exatamente, que está em vias de ser publicado, não é para exibir uma competência que não tenho. Mas tendo lido como historiador, com interêsse sempre crescente o novo trabalho do sr. François Simiand (2), senti seu interêsse e reconheci sua particular utilidade para nossos estudos. $E^{\prime}$ pois natural, que eu o diga aqui.

Falando de economistas e historiadores, não tenho entretanto intenção, e isso se advinha, de entreter velhas questiúnculas. Nada de mais oposto aos fins visados pelos Annales. Mas escrever que os cursos de Economia Política desapontaram durante muito tempo os historiadores, é confirmar simplesmente uma verdade muito banal. Nessas obras eruditas, engenhosas, por vêzes muito bem concebidas e estruturadas, nunca achamos o que mais desejaríamos encontrar (3). Noções positivas e rigorosamente controladas sôbre os diversos modos possíveis de agrupamento, de classificação e de apresentação dos fatos econômicos.

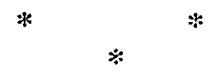

Já se tem assinalado aqui muitas vêzes, a importância de que se revestem os problemas de divisões em todo estudo científico. Por minha vez, venho repetindo isso há 25 anos. Mas quando se pronuncia divisões os historiadores sentem-se logo tentados a entender períodos. E por certo, êles tem diante de si, um problema de períodos - ao qual é permitido, de resto, dar soluções não or-

(1). - A Revista de História julga ser de interêsse para os jovens professôres licenciados pelas Faculdades de Filosofia do país a divulgaçio de algumas questōes de profundo significado, publicadas na revista Annales d'Histoire Économique et Sociale, pouco conhecidas entre nós. Contou para isso com a gentil autorizaçāo do prof. Febvre, da Ed.tôra Armand Colin, bem como a boa vontade do prof. Charles Morazé que selecionou os artigos mais importantes. O presente artigo foi extraído do volume de 1930, 0 . 581590. A tradução do texto francês foi feita pela Licenciada Emília Nogucira ( $E$. Simóes de Paula)

(2). - Cours d'Economie politique, professado em 1928-1929. Paris, Editions Domat Montchrestien; in -8 , policopiado, $654 \mathrm{p}$..

(3). - Os homens da minha geração, entretanto, deveram bastante aos Principes de Schmoller. Mas eu diria que êsse livro clássico era muito histórico para os histo. riadores e näo muito crítico, nem muito realista. 
todoxas: já me referi a isso anteriormente (4). Mas êsse problema não é todo o problema das divisões e quando há alguns anos Charles V. Langlois escrevia: "O estudo teórico dos quadros, isto é, das maneiras mais ou menos legítimas e fecundas de agrupar e arranjar os dados, é uma das partes capitais e sem dúvida uma das menos avançadas da metodologia histórica" (5) - espero que êle não estivesse pensando ùnicamente nos quadros cronólogicos da história, mas nos outros: nessas repartições internas, nessas compartimentagens primordiais, que tão freqüentemente nos livros dos historiadores, levam o leitor aos tempos vizinhos daqueles em que Platão dividia os animais em três grupos: os aéreos, os aquáticos e os terrestres. Se êles se propõem a reconstituir a vida econômica de um determinado quadro territorial, numa certa. época, o "tripartismo" sagrado: Agricultura, Indústria, Comércio, os satisfaz plenamente. Quando muito, modernizando os rótulos escrevem - Produção agrícola, Produção industrial, Circulação dos produtos (6). E se pretendem esgotar a realidade social se satisfarão plenamente com êste agrupamento original e preciso: Clero, Nobrẹza, Burguesia. Fileiras de vagões à última moda Luiz Felipe, que se continua emendando, uns atrás dos outros, segundo a ordem estabelecida pela rotina. Quanto a saber exatamente com o que êles devem ou não ser carregados: mistério. $E$ é assim cue vemos estudos eruditos, anunciando a intenção de oferecer "uma visão de conjunto sòlidamente documentada sôbre a situação econômica" num determinado momento de sua evolução, em tal país importante da Europa Ocidental, tratarem sucessivamente da indústria, do comércio e da agricultura. Eis que desfilam o regime corporativo, e a indústria rural, e as fábricas e as manufaturas centralizadas e as reformas de tal ministro, a política de tal soberano. Perfeito. Ainda uma oficina corporativa e mais um grupo de indústrias rurais e sobretudo fábricas e manufaturas. Mas para fazê-los viver - é necessário o dinheiro, capitais - e capitais que não se destroem perpètuamente mas que a própria atividade dos estabelecimentos, mantem ou multiplica. De onde vêm êsses capitais? Como são empregados? $\mathbf{E}$ quem os emprega? Como são remunerados? Mistério. Chegamos ao comércio: importações, exportações, trânsito, clientes, fornecedores, tarifas aduaneiras, portos. . Perfeito. Mas e a moeda? os preços? "Oferecer uma visão de conjunto sòlidamente documentada da situação econômica..."!? Diante dêsses trabalhos (de resto, tão concencio-

(4). - Cf. no Bulletin du Contre International de Synthèse, anexo à Revue de Synthèse historique, as discussōes em tômo de uma comunicação do sr: Halerki, sôbre as divisōes em história, e particularmente diversas observaçōes apresentadas por mim, na Revure de Synthèse (t. XLII, 1926, p. 30-43), sôbre as "geraçốes" em história, êsse modo de divisão imaginado para. substituir as divisöes pelos atos, por divisōes pelos autores.

(5). - Manuel de Bibliographie historique, p. 581-582.

(6). - A êsse respeito, observaçōes análogas de Marc Bloch em sua nota: Classifica-

tion et choix des faits en histoire économique, réflexions de méthode nos Annales t. I,

1929 , p. 255 . 
sos, e muitas vêzes, ricos de um elogiável labor, em grande parte estéril), penso no prefeito da aldeia lendária onde "nas noites sem lua os habitantes deverão levar ao sair uma lanterna"... E os habitantes levavam suas lanternas. Mas não se lhes havia dito que ai deviam colocar uma vela e acendê-la (7).

Protestar sòmente contra a flagrante insuficiência de tais "classificações" - classificações que não o são - tarefa relativamente fácil, tarefa decepcionante aliás, pois desde que erros semelhantes tem sido assinalados, vêmo-los porventura diminuir? Mais difícil é sem dúvida, substituir com conhecimento de causa êsses antigos magmas de dados heterogêneos agrupados sob rótulos falaciosos, por modos de agrupamento e de articulações dos fatos susceptíveis de se aplicarem às próprias sociedades que se pretende descrever. Eis porque o historiador pede, eis porque o historiador necessita que o economista lhe forneça sôbre êsses difíceis problemas de classificações dos fatos, explicações as mais precisas e as mais nítidas (8). Ele não espera evidentemente que o economista lhe venha fazer a tarefa. Para êle, com ou sem razão, o economista é um obreiro do tempo. presente. Seu objeto, seu campo de investigação é a realidade econômica presente, suas classificações, um meio de aproximar-se o mais possivel das realidades submetidas à análise econômica. Ele sente, nitidamente, desde logo que seria inútil pretender tomar emprestado a seu confrade para transportálos tais como são para o passado, quadros que correspondem a outras necessidades e que devem conter, muitas vêzes uma realidade completamente diferente da realidade histórica. Mas êle necessita que homens competentes the possibilitem executar, sem inúteis tateamentos, uma adaptação necessária de noções comprovadas. Quando aos 20 anos, com sentimentos mistos de admiração e de instintiva rebelião líamos o Année Sociologique, uma das novidades que mais retinha nossa atenção, era o perpétuo esfôrço de correção, de readaptação dos quadros de classificação, os quais de volume em volume se tornavam mais elásticos, se modificavam e sempre com razões que os colaboradores de Durkeim expunham, discutiam, formulavam com clareza. Bela lição de método (9), que êles davam não apenas a seus adeptos declarados - êles tiveram outros discípulos, tenham ou não tido consciência disso, mesmo entre aquêles que refugavam à intransigência de tais ou quais afirma-

(7). - Nāo me seria dificil citar uma recentíssima história do comércio e do seu desenvolvimento, em que os problemas monetários não sāo nem de leve abordados.

(8). - Esses problemas parecem, por outro lado, atrair. cada vez mais a atenção dos economistas. No excelente trabalho apresentado em 1927 L'Etat actuel de la Science économique en France, e que êle retomou depois em seul livro: Doctrines sociales et Science Aconomique, París, 1929, p. 147, o sr. Gaétan Pirou, introduz uma rubrica consagrada ao método da economia política. Devemos observar que as discussóes levantadas em tômo dêsses problemas, estão ainda muito contaminados pelo subjetivismo, cada autor defendendo seu sisterna contra os sistemas de outrém, sem se preocupar muito em oferecer uma crítica objetiva das noções que utiliza.

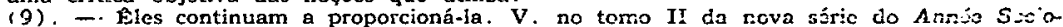
logique (fasciculo 1, 1927), o artigo de Marcel Mauss, Divisions et proportions des divisirns de la Sociologie, p. $98-173$. 
ções suas, porque nesses tempos longínquos êles eram jovens como nós - e não se preocupavam em usar meias medidas.

*

*

Portanto, dados abundantes e bem criticados, que nos permitam conciliar nossa prática com a dêles - isto é, adaptar aos fatos de nossa alçada, tal modo de classificação que satisfaça plenamente à tôdas as necessidades. Para que possamos utilizar êsses dados como convêm, uma ou duas precauções são entretanto necessárias, ou mais exatamente, uma condição é necessária. Habituados à pesquisa paciente dos fatos - obsedados por outro lado pela idéia de datar com precisão, de circunstanciar no tempo e no espaço todos os elementos de nossos trabalhos, somos freqüentemente incapazes de utilizar as noções abstratas que os economistas nos fornecem. Não porque sejam abstratas, mas porque são deduzidas. Deduzidas de premissas puramente arbitrárias e que traduzem em linguagem de conceitos reações puramente subjetivas. Não me refiro aos autores que se declaram abertamente advogados, propagandistas de uma doutrina de ação e tentam demonstrar que ela é a única científica. Refiro-me, quero referir-me a tratados, a manuais, a cursos que pretendem ser obras de ciência; e que confessam apenas um propósito: aquêle que êles chamam da verdade científica. Muito mais decepcionantes são êles, quando os lemos com nossas preocupações: quero dizer, com esta idéia latentẹ: o economista desmontando como deve fazer e como tenta fazê-lo a mecânica das sociedades contemporâneas, descreve-nos em suma o ponto de coroamento atual de inúmeras séries de fatos que apreendemos em momentos diferentes do passado e que são objeto de nosso estudo particular (10). Se os métodos de investigação dêsse economista são corretos, se sua observação é escrupulosa e aprofundada, é verdadeiramente impossível que a posse intelectual da realidade presente que graças a êle vamos ter, não nos ajude a armar êsse quadro de presenças e ausências indispensável a todo investigador do passado que não deseje fazer essa inepta caricatura do presente, dà qual tantos livros, pretensamente sérios, só nos oferecem a imagem estéril. Mas como poderíamos, como conseguiríamos, legitimamente nos inserir mentalmente, com nossas preocupações particulares, na trama homogênea dos conceitos nascidos de especulações a priori? Seus autores apelam para a observação, mas para obter dela aquilo que não só thes demonstre que os fatos justificam suas idéias preconcebidas, como também os ajude a demonstrá-lo aos demais.

(10). - Sôhre, a atitude geral dos economistas franceses diante dos problemas de método vide o trabalho sá citado do sr. Gaétan Pirou, p. 111 e segs. 
Ora, em três anos, de 1927-1928 a 1929-1930, o sr. François Simiand, professou no Conservatório de Artes e Ofícios, um curso de Economia. As lições do segundo ano aparecem hoje policopiadas. As dos outros anos virão em seguida (11). Não esperemos mais para recomendar essa obra vigorosa e precisa fundamentada num poderoso esfôrço de análise do real, não aos economistas (êles não precisam que alguém os incite a ler um livro do sr. Simiand), mas a todos e em particular aos historiadores. Tanto mais que ela precisamente parece feita para corresponder aos desejos que manifestávamos.

Observação que a alguns de nossos contemporâneos poderá parecer talvez um pouco paradoxal, pois, se há um homem que tenha dito outrora duras verdades aos hitoriadores - (e quando digo verdade, sei bem que palavra emprego) - êsse homem é precisamente o sr. François Simiand. Não despertemos velhos ecos, sempre prontos a repetir títulos e nomes: títulos de artigos vigorosos, sob a pressão dos quais estalou em outros tempos o verniz da certeza tranqüila com o qual saíamos completamente recobertos graças aos cuidados de nossos bons mestres; ou ainda, nomes de autores, nömes de historiadores sacudidos por u'a mão firme, por um pulso enérgico, por um crítico de rara visão (12). Tudo isso é verdade. Mas em primeiro lugar, é permitido mesmo a um historiador (sobretudo a um historiador), pensar que todos aquêles que amam a história podem se regozijar dessa ação violenta. Apesar da rotina e das funestas consequiências de uma formação paradoxal, ela deu alguns frutos. Ninguém precisa por certo, renunciar a suas idéias e ao seu ponto de vista doutrinário particular. Mas o que domina tudo, o que tudo sobreleva é que o sr. Simiand parte de um postulado e precisamente dêste: a ciência econômica tendo por objeto conhecer e explicar a realidade econômica, deve atíngi-lo não através de deduções, mas por métodos semelhantes aos das ciências indutivas, particularmente pelo uso de uma estatística que êle considera de maneira tão nova quanto original, como uma espécie de pesquisa experimental.

Não indaguemos se as idéias que o sr. Simiand expôs em seu pequeno livro - tão novo e tão rico: Statistique et Expérience,

(11). - Indiquemos sumàriamente as principais questões tratadas no volume já aparecido: I) Produção: a questão đo racionalismo económico (estudo dos fatos nos U. S. A., Alemanha, França); - funcionamento econômico da emprêsa; do ramo da atividade econômica (indústrias primárias de transformaçāo, comércio de atacado e comércio de varejo; banco e bolsa); - o movimento global e os índices de produçāo; o movimento geral $e$ os indices de preço; - de onde vem a riqueza produzida (capital, trabalho). II) Repartição: as classes sociais; - instituiçôes da repartição (sindicatos, assistência, socorros mútuos, seguros); - a riqueza privada (os patrimónios e as rendas). E' desnecessário observar que se trata sempre não de deduçōes abstratas ou impressões pessoais - mas de pesquisas positivas sôbre os fatos, que precedem e condicionam as conclusões, cuidadcsamente relacionadas com as primeiras.

(12). - F. Simiand, Méthode historique et science sociale na "Revue de Synthèse historique", 1903, t. VI, p. 1 e 129; em réplica P. Mantoux, Histoire et Sociologie, Ibidem, 1904, t. VII, p. 121. F. Simiand, La causalitét en histoire no "Bulletin de la Société Française de Philosophie", 1906-1907. E no Année Sociologique, entre outros, a resenha (1905-1906, p. 589), da tese de $\mathbf{P}$. Mantoux, La revolution industrielle au $X V I I I^{c}$ siècle. 
Remarques de méthode (13), podem, à custa de uma adaptação cuidadosa interessar igualmente à história. Nem se não seria desejável que o historiador tentasse substituir os sistemas complexos de causas e efeitos diante dos quais sua pesquisa o coloca, por sistemas simples e se possivel combinados de maneira a se poder reter as variações de uma única circunstância causal e não de muitas. Há muito que numa resenha do Année Sociologique, o sr. Simiand, já notava, com muita razão: analisar o real com categorias claras e precisas e aí estudar as relações de maneira geral, se bem que sempre próximas da realidade, não é afastar-se dêle, e lançar-se em construções lógicas e artificiais; - apenas essas categorias e essas relações dão uma verdadeira compreensão da própria complexidade do real (14).

$O$ instrumento de tais pesquisas parece ter sido encontrado: é a estatística; e a objeção de que ela data de ontem não serve. Objeção de fato, não de método: pois nestes cem anos não começa a história a dispor de dados estatísticos, para tôda uma parte de seu território, dados êsses que também ela poderá utilizar para seus próprios fins? Nessas pesquisas estatísticas que se multiplicam sob nossos olhos não se incluem já, para aquêles que sabem ver, capítulos inteiros de história de sociedades hoje vivas, amanhã históricas? (15). Recebemos recentemente nos Annales o belo livro do sr. Ferenczi, International Migrations (16), com estatísticas que remontam, muitas vêzes, a mais de um século, ou abrangem sempre, pelo menos, mais de meio século. Nessas 1100 páginas compactas não se inscreve já de maneira gritante, um capítulo da história do mundo? Há quem acredite que a história poderá, a não ser que se transforme definitivamente em não sei que inútil rapsódia pedagógica, ignorar por muito tempo tais esforços e os historiadores contentarem-se com a paleografia e a diplomática como ciências auxiliares? Sim, mutilando-se a história; cavando-se novos fossos, elevando-se novas muralhas chinesas. Sim, desviando-se os olhos do futuro.

Deixemos isso. Ó que nos interessa é que uma obra, impregnada dêsse espírito que definimos acima, foi feita, ao contrário de tantas outras, para prestar aos historiadores alguns dos serviços essenciais, que êles tem direito de esperar dos economistas. Já que não podemos hoje, tendo diante de nossos olhos, apenas um

(13). - Na Bibliothèque des Siences économiques et sociales, París, M. Rivière, 1922, in-16, $68 \mathrm{p}$.

(14). Ano 1905-1906, p. 504 .

(15). - $O$ sr. Mauss, observa por sua vez no Année Sociolodique (nova série, t. II, fascículo I, 1927, p. 152). "Em nossos dias, nos trabalhos imensos como os do Censo americano ou do Censo das fndias, vê-se aparecer através das estatísticas compiladas, fenômenos sociais em ebulição; caldeira da feiticeira, onde se fabrica uma sociedade". Por outro lado, sôbre as possíveis aplicaçóes de medidas quantitativas aos problemas de história geral vide o pequeno livro de A. Niceforo, Les Indices numériques de la Civilisation et du Prosrès. Paris, Flammarion, 1921, in-16.

(16) . Publication of the National Bureau of Economic Research, New York, 1929. in-8, 1112 p., ver o resumo de Demangeon nos Annales t. II, 1930, p. 418. 
fragmento do curso do sr. Simiand, nos apegar aos problemas de classificação e numa visão de conjunto observar como, em que plano, e segundo que concepções examina êle um por um os diversos conjuntos de fatos que reconheceu e constituiu (17), tentemos demonstrar, a respeito de uma questão particular, como o trabalho do economista e o do historiador podem auxiliar-se reciprocamente e reforçar-se um ao outro.

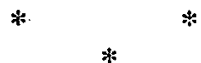

Na parte publicada do seu curso, o sr. Simiand é levado a tratar đe uma questão muito importante - tão cheia de interêsse para o historiador quanto para o economista: a das Classes sociais.

$O$ que é uma classe? Um grupo de indivíduos tal que entre os membros dêsse grupo, existem certas relações que não são as mesmas entre êsses membros e as pessoas estranhas ao grupo. E além disso, o fato dessas relações devidamente averiguadas não serem transitórias, sem consistência por assim dizer e quase acidentais, mas duráveis e mesmo por vêzes, hereditárias (18). Eis o que é relativamente fácil de se dizer. Mas onde tomar êsses grupos? Como delimitá-los? Bastaria simplesmente apurar os ouvidos e confiar na linguagem dos homens? Procedendo assim verificaríamos duas coisas: Uma, que hoje não há mais classes e outra, que há uma infinidade de classes: uma classe patronal, uma classe obreira, uma classe média, uma classe agrícola, uma classe de empregados, uma classe burguesa, etc., etc.. Contradição fundamental - e anarquia de julgamentos.

Por certo, num país como a França, é verdade que desde a Revolução que declarou os homens livres e iguais em direito, não existem, juridicamente falando, classes distintas dotadas de privilégios reconhecidos quer pelo direito escrito, quer pelo costume, e mantidas por interdições tão fortes quanto como, por exemplo, a do casamento entre membros de grupos diferentes. Esse fenômeno não está em tôda a Europa tão avançado quanto em .França, mas em tôda a parte êle, desde há muito, vem se realizando. Deve-se pois concluir que "não há mais classes?" Não. Apenas que uma transformação se operou no modo de definir e na maneira de caracterizar as classes.

Observação muito importante para o historiador. As classes se definem, nota o sr. Simiand, no plano daquilo que os homens, numa certa época, mais apreciam - aquilo que dá a consideração e implica no poder, na autoridade, nos meios de ação, numa

(17). - De uma maneira geral indicamos simplesmente que essa classificação é a mesma que o sr. Simiand estabeleceu pouco a pouco no Année Sociologique (quinta secçäo, Sociologie Economique). A êsse respeito consulte-se sua anotação: "nossa classifização dos trabalhos econômicos" no Année Sociologique, nova série, t. I, 1923-1924, p. 720-724. (18). - Curso p. 440 . 
determinada sociedade (19). Trata-se de sociedades de base religiosa? 'Será o grau de pureza que distinguirá as classes e isolará uma das outras. Trata-se de sociedades guerreiras, de base militar? Será o fato de se ser ou não portador de armas, ou ainda de se passar por descendente ou dos vencedores e conquistadores, ou dos vencidos e conquistados. Nas sociedades legalistas fundamentadas sôbre as distinções de direito cívico ou político, teremos classificações de essência jurídica em livres e não livres, em patrícios e plebeus, burgueses e vizinhos, etc.. Entretanto, as coisas não são nunca assim tão simples: uma sociedade nunca se abisma no nada sem deixar traços. Os montes-testemunhos não são encontrados aperas na superfície do solo físico para orientação de geógrafos. A história social está cheia dêles. Uma quantidade prodigiosa de idéias, de noções de formas sociais herdadas do passado persiste em cada época, nas camadas mais ou menos profundas da população. E é muito raro que o princípio que racionalmente deveria presidir numa certa época, a formação e a apreciação das classes, vigore sòzinho e atui livremente em terra virgem. Maurice Halbwachs em seu livro Les cadres sociaux de la mémoire, observa-o muito bem: não é em virtude de um esfôrço consciente dos membros de uma sociedade, que se outorgariam novas instituições em vista das vantagens reais que delas tirariam, que uma sociedade passa de uma organização para outra (20). As instituições novas não se thes impõem enquanto não tenham êles experimentado os seus benefícios, a não ser que o mesmo prestígio que envolve as instituições mais antigas venha envolvê-las. $\mathbf{E}$ é assim que nossas sociedades permanecem sempre lastradas com o pêso de uma parte mais ou menos grande do seu passado. Até o dia em que uma revolução venha efetuar uma espécie de higiene, um desentulhamento mais ou menos radical dos escombros históricos. Mesmo assim, êsse desentulhamento raramente é completo (21).

Assim se explica, por exemplo, o papel desempenhado até bem pouco tempo, em nossas sociedades, pelo clero ou pela nobreza de espada: classes constituidas, uma no plano religioso, outra no plano militar e que embora evoluindo e adaptando-se continuaram a se manter, durante séculos, no meio de sociedades que de mais a mais se organizavam em um outro plano.

Que plano? O plano econômico. As classes se definem hoje, cada vez mais, no plano econômico - isso é um fato, e o sr. Simiand bem o focaliza (22). Não que ignoremos as sobrevivências ou que os montes-testemunhos estejam ausentes das nossas paisagens. Mesmo num país de velha cultura democrática como a

(19). - Curso p. 442

(20). - París, Alcan, 1925; in-8 p. 302.

(21): - A êsse respeito veja-se o pequeno e recente livro de Henri Sée, Evolution et Révolution. París, Flammarion, 1929, in-12, p. 247-248.

(22). - Curso p. 443 . 
França, subsistem grupos que tornam atual a conhecida máxima: "dois homens são da mesma classe quando suas mulheres se freqüentam". Mas enfim, no conjunto e mais do que nunca, o princípio triunfa: nossas classes são na medida em que elas existem, de origem e natureza econômica. Eis o que nos explica o lugar que elas ocupam no curso do sr. Simiand. Ou melhor, eis o que justifica ter o autor colocado êsse estudo precisamente à frente dos capítulos consagrados à Repartição. Esses capítulos tratam sucessivamente da organização e depois do funcionamento da Repartição: a anatomia primeiro, a fisiologia depois. Ora, quem estuda a organização da produção deve aplicar-se a consideração dos produtos, quem estuda à da repartição, a consideração das pessoas. Essas pessoas não vivem isoladas, no estado de poeira humana. Elas são na vida corrente, objeto de classificações familiares aos homens das diversas épocas - a noção de classe social apresentase assim, muito naturalmente, no próprio quadro do estudo econômico, e num lugar perfeitamente racional. Devemos concluir daí, que todo estudo das classes de uma determinada sociedade, deve ser igualmente enquadrado e localizado nesse lugar determinado? Evidentemente não, temos que repetí-lo. Não, porque as grandes linhas da estrutura econômica e as apreciações dos homens sôbre os valores da existência não permanecem idênticas e comparáveis, de sociedade para sociedade (23).

E como indicamos mais acima, é o problema da classificação que se alça diante do historiador, particularmente diferente, é claro, de como aparece para o economista. Sob que aspecto se apresenta o problema para êste, em se tratando do estudo presente de nossas sociedades européias? Ou mais exatamente: como se coloca êle, para o sr. Simiand? Vai êle agir, como tantos outros por inspiração, retalhar a seu bel prazer grupos que chamará classes e que a linguagem corrente permitirá, como vimos, fàcilmente rotular? Não, absolutamente. E' para a estatística que êle vai apelar. A que tende ela? Ele já o disse há alguns anos: "permitir ao espírito humano fazer de conjuntos complexos, uma representação relativamente simples, apreciar o valor dessas representações simplificadas, estudar e reconhecer se elas entretêm relações entre si, e com que fundamento e até em que grau essas relações se estabelecem (24). Mas não há aí, precisamente nessa frase, o verdadeiro programa de uma pesquisa das classes?

$\mathrm{E}$ eis a pesquisa que começa, o método que se aplica. Cenário - a França, país ao mesmo tempo representativo do movimento contemporâneo e muito rico em realidades continuadas do passado no presente. Em primeiro lugar: extensão, delimitação dos grupos. Começa-se pelas divisões mais amplas. Há aquêles que

(23). - Curso p. 442

(24). - Statistique et Expérience, p. 7. 
trabalham - entendamos - que exercem uma profissão remunerada; há os outros. Ora, a proporção dos primeiros para os segundos varia: 1866 , para o sexo masculino $55 \%, 1896$ a $190168 \%$, $192771 \%$. Mas nessa população ativa, não podemos determinar agrupamentos secundários? Sim. Categoria obreira (inclusive empregados), $60 \%$ da população ativa. Categoria patronal, o resto. Não continuemos. Não pretendemos resumir de uma maneira esquemática, uma pesquisa que vale pelo método e por um contrôle permanente de um espírito crítico excepcionalmente desperto e bem dotado. $E^{\prime}$ evidente que aqui, a estatística fornece - desde que manejada não por um estatista improvisado, mas por um mestre - um conjunto de dados fundamentais, os únicos que permitem ver com clareza em situações tão complexas e embaralhadas como as das sociedades modernas.

Ela não oferece apenas dados precisos e importantes sôbre a extensão dos grupos, sua importância numérica e suas relações. Permite satisfazer outras curiosidades. E desde logo, examinar com objetividade a importante questão da permanência, ou como diz o sr. Simiand, "da durabilidade na condição" - indispensável para que uma categoria econômica possa ser considerada como constituindo uma classe. Porque os aprendizes, por exemplo, não constituem uma classe. E se não existem recenseamentos contínuos que permitam acompanhar os indivíduos através de tôda a sua vida, existem entretanto, meios indiretos de descriminações. Entre outros, as estatisticas de idade, que para a França fornecem os últimos recenseamentos. E se formulássemos a questão dos aprendizes, ela permitiria determinar que há aprendizes no sentido mais amplo do têrmo, de 13 a 25 anos, mas que abaixo e acima dessas idades, não figura mais ninguém sob essa rubrica, não nos encontramos portanto, em presença de uma classe. Outra questão não menos importante - a da família. A classe comporta igualmente a mulher e os filhos. E sob êsse ponto de vista quantas questões! A mulher trabalha ou não? e os filhos? Tal grupo, o grupo patronal, por exemplo, tem mais filhos que aquêle outro? Como se distribuem, em cada grupo, êsses filhos, por famílias? Varia a proporção de grupo para grupo, com a idade? Também aqui, não continuemos. Já dissemos o bastante para que se perceba o método e se the adivinhe a fecundidade.

Voltamos à nossa constante preocupação. Que poderemos tirar daí, para nós - historiadores? Resultados a serem utilizados tais como se apresentam? Processos de investigação a serem transportades do presente para o passado sem modificação, ou pelo menos com a intensão de modificá-los o menos possível? Evidentemente não.

Os processos? Mas se mal aparelhados para começar estudar as sociedades contemporâneas com a ajuda de estatísticas ainda bem incompletas e insuficintes, nós não o estamos, de maneira al- 
guma, para empreender da mesma forma, e segundo os mesmos métodos, o estudo e análise das sociedades "históricas", quaisquer que sejam. Os resultados? Nós escrevíamos - permitam-nos lembrá-lo - no primeiro fascículo de nossos Annales: não falemos da função industrial dos portos no tempo em que não havia indústria no sentido atual da palavra e lembremos sempre que não foram ùnicamente os fatos materiais mas também as mentalidades que se diferenciaram profunda, senão radicalmente do tempo de nossos bisavós para o nosso (25). Escrevíamos, porém, na mesma ocasião e no mesmo local - e não podemos deixar de repetí-lo: um conhecimento preciso dos fatos e do mundo contemporâneo só pode exercer no espírito do historiador uma grande fôrça de sugestão. Ele nos permite formular problemas com os quais nunca sonharíamos, que de fato não formulamos sem êsse exemplo e ajuda. Ele nos permite elaborar uma espécie de quadro das presenças e ausências, bem como das semelhanças e das diferenças - quadro êsse que é para nós um instrumento de investigação absolutamente indispensável. Uma comparação entre o presente e o passado é fecunda tanto por seus resultados negativos como pelos positivos. Isso nos conduz a um problema ainda mais amplo. Nossas classes, as classes que nós bem ou mal tentamos distinguir nas sociedades atuais e que só uma análise precisa e que domine os fatos como a que faz o sr. Simiand, permite apreender de maneira clara e objetiva - nossas classes as quais tão freqüentemente nos referimos, e cujas relações, conflitos e lutas nos parecem constituir um dos traços permanentes e verdadeiramente fundamentais da história humana - são agrupamentos de ordem ou melhor de origem econômica. Ora, sob pretexto de tornar nossos estudos mais vivos, de "renovar" a história e de "modernizar" a sua compreensão, procuramos encontrar - o que em realidade significa, que tentamos projetar em sociedades muito antigas, estabelecidas sôbre bases de origem éconômica, classes alicerçadas na fortuna e que são categorias que nos são familiares - êsses grandes atores coletivos que representam para nós o drama do presente - isto é, as classes de origem econômica, classes alicerçadas na fortuna e que são perfeitamente localizadas no estudo da repartição, tal como o orienta o sr. Simiand. A técnica nos parece legítima (26). Sêlo-á realmente? E quando tentamos instalar em meios que se organizam num plano completamente diferente do plano econômico, categorias de origem e significado econômico - portanto filhas do presente, não estamos em realidade executando um trabalho arbitrário, fictício e estéril? Assim o creio, e essa é a meus olhos a ob-

(25). - Ports d'autrefois, ports d'aujourd'hui, nos "Annales", t. I, 1929, p. 98.

(26). - Como é falso determinar-se a condição sosial dos homens em tôdas as épocas, pela sua riqueza, pela quantidade de bens móveis ou imóveis que possuam. Quase todos nossos estudos sôbre as classes medievais, estão viciados por essa confusão. 
jeção grave que se pode opor a um certo materialismo histórico, ao mesmo tempo sedutor e grosseiro, verdadeira negação, se penetramos no âmago das coisas, do espírito histórico e da tarefa particular do historiador. Porque recompor tardiamente o passado, restabelecendo-lhe a estrutura interna sôbre um plano que êle jamais conheceu, compreendeu ou admitiu, não é compreendê-lo, é, sim, desfigurar-lhe os aspectos essenciais.

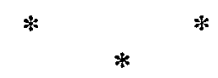

François Simiand - ou as candições de pesquisa em 1936 (27).

O sr. Max Lazard consagra uma nota documentada, simpática e compreensiva à personalidade e à obra de Fr. Simiand. Ela faz sentir muito bem, a originalidade da obra e do método de Simiand, como também focaliza a capacidade de trabalho e as delicadas e discretas qualidades do homem. Detenhamo-nos apenas na última página: "Não é por centenas, mas por milhares, ou mesmo dezenas de milhares, que durante êsses trinta anos de labor, Simiand, escravo de seu método, fêz cálculos, elaborou quadros de algarismos, estabeleceu gráficos. Ao fazer isso êle sonhava com laboratórios de ciência social, nos quais um chefe dirigiria as pesquisas de seus assistentes e os trabalhos materiais de técnicos escolhidos. Mas êle mesmo não tinha nem assistente nem técnicos..." Quem dentre nós não teve - não tem, sonhos iguais ao de Fr. Simiand? Quem pode duvidar que êle se tenha esgotado em tarefas dêsse gênero, nesse trabalho de beneditino alucinado, que haja nisso um tremendo desperdício de fôrças humanas, e que a história econômica encontre nisso, um dos obstáculos mais difìcilmente transponíveis, a seus progressos regulares. O sr. Lazard nota que quando se trata de indagar o menor detalhe de um fenômeno químico ou físico, nós nos conformamos fàcilmente com a aridês de semelhantes trabalhos, mas que ela desanima o homem médio, impaciente de chegar em questões de ordem social a conclusões de ordem prática. E' verdade. Mas o trabalhador que se dedica à física ou à química, está fortemente enquadrado num laboratório que não é sòmente um local de pesquisas, mas um centro organizacio de trabalho metódico. Sua contribuição inserir-se-á nos trabalhos do laboratório. Ele ficará satisfeito com isso. Ele sabe, muito bem, que assim ela não está perdida, muito ao contrário - e que por outro lado, êle próprio, do ponto de vista da sua carreira, não perderá suas vantagens, que inscrita no seu ativo ela

(27). - A presente nota também foi publicada por Lucien Febvre in Annales d'Histoire Economique et Sociale, janeiro de 1936 , p. 42 . Assim tomamos também a liberdade de juntá-la, por ser uma idéia que precisa ser retida e divulgada entre nós. Que sirva para meditação. (Nota da tradutora). 
será encontrada no dia que quiser. O economista e o historiador ambicionam mais. A autonomia enganosa do livro assinado, independente, autônomo. A obra pessoal. A obra de arte, econômica ou histórica. Enquanto êsse estado de espírito não 'tiver desaparecido, enquanto o trabalho em cooperação não for instituido - nada se poderá fazer. Mas para que êle seja instituido, é preciso que a pesquisa histórica, ou econộmica, seja considerada como uma função necessária, retribuida e organizada como tal. E' necessário que haja laboratórios, que abriguem equipes de sábios de formação diversa. Não nos cansaremos de repetir. Simiand mostrou o caminho. Ele salvou a honra. Morreu por ela. Que tenha sido, ao menos, por alguma coisa. 